\title{
Fatores de risco e medidas profiláticas nas pneumonias adquiridas na comunidade
}

\author{
LUCY GOMES ${ }^{1}$
}

\begin{abstract}
Este artigo revisa os efeitos do envelhecimento, tabagismo, DPOC, insuficiência cardíaca, colonização da orofaringe, aspiração (micro e macro), alcoolismo, cirrose hepática, deficiência nutricional, imunossupressão e fatores ambientais sobre o risco de adquirir pneumonia na comunidade e sua gravidade. Na segunda parte, é feita revisão sobre a ação profilática das vacinas antiinfluenza e antipneumococo, assim como a ação das drogas antivirais, na profilaxia e tratamento das pneumonias adquiridas na comunidade. (J Pneumol 2001;27(2):97-114)
\end{abstract}

\section{Risk factors and prophylaxis of community-acquired pneumonias}

This article reviews the effects of aging, tobacco-smoking, chronic bronchitis and emphysema, heart failure, oropharyngeal colonization, aspiration (micro and macro), alcoholism, hepatic cirrhosis, nutritional deficiency, immunosuppression, and environmental factors on the risk of community-acquired pneumonia and its severity. In the second part, the authors review the prophylactic action of anti-influenza and anti-pneumococcus vaccines as well as the role of prevention and treatment of antiviral agents in community-acquired pneumonia.

Descritores - Pneumonia pneumocócica. Influenza. Vacina contra influenza. Vacinas virais. Fatores de risco.

Key words - Pneumococcal pneumonia. Influenza. Influenza vaccine. Viral vaccines. Risk factors.

A pneumonia pneumocócica e a influenza são infecções do trato respiratório inferior que levam a significante morbidade e mortalidade, especialmente em determinadas populações (como de idosos e aquela com doenças cardiopulmonares)(1). Nos Estados Unidos, enquanto taxas de hospitalização têm decaído como um todo, hospitalizações por infecções do trato respiratório inferior têm aumentado progressivamente desde $1980^{(2)}$. A infecção pneumocócica invasiva leva à bacteremia e meningite. Nos Estados Unidos, a incidência anual estimada de bacteremia pneumocócica entre idosos é de 50 a 83 casos por 100.000 pessoas, sendo tais infecções associadas a alta taxa de fatalidade ${ }^{(3)}$. Os fatores de risco para doença

1. Professora Titular de Clínica Médica, Universidade de Brasilia (UnB); Coordenadora da Área de Geriatria do Curso de Pós-graduação em Ciências da Saúde, UnB.

Endereço para correspondência - SHIS QL 18, conj. 7, casa 10 71650-075 - Brasilia, DF. Tel. (61) 366-2538.

Recebido para publicação em 31/5/00. Reapresentado em 31/ 10/00. Aprovado, após revisão, em 1/11/00.
Siglas e abreviaturas utilizadas neste trabalho

DPOC - Doença pulmonar obstrutiva crônica

FUNASA - Fundação Nacional de Saúde

SUS - Sistema Único de Saúde

AIH's - Autorizações de Internação Hospitalar

PAC - Pneumonias adquiridas na comunidade

$\mathrm{RR}$ - Risco relativo

AVC - Acidente vascular cerebral

UTI - Unidade de terapia intensiva

HIV - Virus da imunodeficiência humana

AIDS - Síndrome da imunodeficiência adquirida

CDC - Centers for Disease Control and Prevention

OMS - Organização Mundial de Saúde

pneumocócica e influenza sobrepõem-se, pois a pneumonia é a complicação mais comum da influenza e o organismo mais freqüentemente implicado é o $S$. pneumoniae $e^{(4)}$. Avanços na prevenção dessas infecções foram alcançados com o uso das vacinas.

Em um ano comum, um entre cada dez adultos é portador de influenza (gripe). Na população pediátrica, as percentagens anuais de incidência relatadas por clínicas ultrapassam os $30 \%$. A morbidade é concentrada em crianças em idade escolar e adultos saudáveis, porém as percentagens mais elevadas de mortalidade, decorrentes da infecção pelo vírus da influenza, ocorrem em indivíduos 
maiores de 65 anos. São relatados 10.000 a 40.000 óbitos relacionados à influenza, somente nos Estados Unidos, para cada época sazonal de gripe. Naquele país, a infecção pelo vírus da influenza resulta em 25 milhões de consultas médicas anualmente, milhões de dias de trabalho perdidos e centenas de milhares de hospitalizações. O impacto econômico anual associado à influenza constitui grande ônus para a sociedade, sendo estimado, nos Estados Unidos, em US\$ 12 bilhões anualmente $e^{(5)}$.

No Brasil, as pneumonias foram a causa básica de 17.220 mortes na faixa etária de 65 anos ou mais, durante o ano de 1996. De acordo com o Serviço de Vigilância Epidemiológica da Fundação Nacional de Saúde (FUNASA), a taxa de hospitalização por gripe e pneumonia em idosos foi de 12,5 por 1.000 habitantes. Os dados de hospitalização do Sistema Único de Saúde (SUS) demonstram que a pneumonia é a terceira causa de internações entre indivíduos com 65 anos de idade ou mais, representando $6,8 \%$ do total de internações hospitalares no SUS, com um custo médio unitário de $\mathrm{R} \$ 194,09$. Em 1997, 17,8\% das Autorizações de Internação Hospitalar (AIHs) foram decorrentes de doenças respiratórias agudas e pneumonia em idosos, representando um custo de $\mathrm{R} \$ 99,7$ milhões $^{(6)}$.

A seguir, discutiremos os seguintes fatores de risco nas pneumonias adquiridas na comunidade (PAC): envelhecimento, tabagismo/DPOC, insuficiência cardíaca, colonização da orofaringe, micro e macroaspiração, alcoolismo/cirrose hepática, deficiência nutricional, imunossupressão e fatores ambientais. Os mesmos estão listados no Quadro 1.

\section{FATORES DE RISCO}

\section{EFEITOS DO ENVELHECIMENTO}

Não está definido se a idade é fator independente de risco da PAC. Fine et al. ${ }^{(7)}$, excluindo pacientes com doenças crônicas, identificaram a idade maior que 65 anos como fator de risco independente para pneumonia complicada. Entretanto, a idade não teve peso preditivo alto, sendo algumas das complicações de pouca significância. Assim, é incerto se o envelhecimento, em pacientes ativos na comunidade sem comorbidade associada, leva a

\section{QUADRO 1}

Fatores de risco para pneumonias adquiridas na comunidade

- Envelhecimento

- Tabagismo/DPOC

- Insuficiência cardíaca

- Colonização da orofaringe

- Micro e macroaspiração aumento do risco de PAC complicada. É provável que a idade e comorbidade sejam aditivos e talvez sinérgicos, com respeito ao mau prognóstico da PAC. O paciente idoso, sem condições de risco associadas, tem taxa de morte anual por pneumonia ou influenza de 9 por 100.000, comparada com 217 por 100.000 naqueles com condição de alto risco e 979 por 100.000 naqueles com duas ou mais condições de alto risco ${ }^{(8)}$. O aumento da incidência de PAC com a idade é melhor explicada pela combinação de alteração do estado imune, em adição a aumento da comorbidade.

As alterações dos mecanismos de defesa no paciente idoso, sejam mecânicas ou senescência do sistema imune, estão mostradas no Quadro 2. Além disso, as comorbidades que podem influenciar negativamente as defesas do hospedeiro estão listadas no Quadro 3.

A progressiva involução da glândula tímica pode ter papel importante no desenvolvimento da imunodeficiência característica dos idosos ${ }^{(9)}$. As células $T$ dos idosos têm deficiência em sua habilidade para ativar e proliferar em resposta a um antígeno. Em adição, a habilidade das células $\mathrm{T}$ para secretar interleucina-2 (uma citocina necessária para recrutamento de outras células T) diminui com a idade. A resposta anticórpica alterada para antígenos estranhos parece ser secundária à deficiência das células $\mathrm{T}$ helper. O recrutamento de macrófagos por células $\mathrm{T}$ está diminuído no idoso, assim como podem também estar alteradas a quimiotaxia dos neutrófilos polimorfonucleares e a fagocitose ${ }^{(10)}$.

\begin{tabular}{|l|}
\multicolumn{1}{c|}{$\begin{array}{c}\text { QUADRO } 2 \\
\text { Mecanismos de defesa do hospedeiro idoso }\end{array}$} \\
\hline 1. Alterações mecânicas \\
- Aumento homogêneo dos espaços aéreos \\
- Perda da elasticidade \\
- Alteração do reflexo da tosse \\
- Diminuição do clearance mucociliar \\
\hline 2. Alterações Imune - Locais \\
- Diminuição da IgA secretória? \\
\hline 3. Alterações Imune - Sistêmicas \\
- Involução da glândula tímica \\
- Diminuição do hormônio tímico \\
- Diminuição na maturação das células T \\
- Diminuição das células T imaturas circulantes \\
- Diminuição da taxa CD $/$ CD \\
- Diminuição das células T helper \\
- Diminuição na habilidade das células T para dividir \\
- Diminuição na resposta das células T para IL-2 \\
- Diminuição na produção de anticorpos para antígenos es- \\
- tranhos Aumento dos anticorpos para auto-antígenos \\
\hline
\end{tabular}

- Alcoolismo/cirrose hepática

- Deficiência nutricional

- Imunossupressão

- Fatores ambientais 


\begin{tabular}{|l|}
\multicolumn{1}{|c|}{$\begin{array}{c}\text { QUADRO } 3 \\
\text { Efeitos das doenças crônicas nas defesa do hospedeiro }\end{array}$} \\
\hline 1. Diminuição da imunidade mediada por células: má nutrição, diabetes mellitus, insuficiência hepática \\
2. Diminuição da imunidade humoral: insuficiência renal, má nutrição, insuficiência hepática \\
3. Alteração na colonização da orofaringe: má nutrição, câncer \\
4. Neutropenia: câncer \\
5. Alteração da resposta dos macrófagos e neutrófilos: insuficiência renal, diabetes mellitus, cirurgia, trauma \\
6. Alteração da drenagem linfática: doenças cardíacas \\
7. Risco de aspiração: doenças neurológicas \\
8. Alteração da tosse e clearance mucociliar: DPOC, asma, tabagismo \\
\hline
\end{tabular}

A etiologia e a gravidade das PAC estão relacionadas com a idade e as comorbidades apresentadas pelos pacientes. A presença de doenças crônico-debilitantes associadas ao envelhecimento é fator preponderante relacionado com o risco de morbidade e mortalidade nessa população. Certas doenças crônicas, especialmente aquelas relacionadas ao sistema cardiovascular e pulmonar, estão presentes em 6 a $56 \%$ dos pacientes com PAC tratados em domicílio e em 23 a $92 \%$ daqueles que necessitam de internação hospitalar ${ }^{(11)}$. Estas comorbidades predispõem à PAC por bacilos gram-negativos e Pseudomonas aeruginosa ${ }^{(12)}$. Tabagismo, doença cardiovascular, doença pulmonar obstrutiva crônica, doença maligna e diabetes mellitus são as condições básicas que predispõem à pneumonia pneumocócica. Watanakunakorn e Bailey ${ }^{(3)}$ relataram que $36,8 \%$ dos pacientes com 85 a 95 anos morreram de pneumonia pneumocócica, enquanto esta causa de morte não ocorreu em nenhum paciente com idade inferior a 45 anos. Assim, a exclusão do tabagismo e o tratamento das doenças básicas, principalmente no paciente idoso, mantendo o mais perto possivel da normalidade as defesas imunológicas sistêmicas e locais pulmonares, vão ajudar na prevenção da pneumonia.

Koivula et al. ${ }^{(11)}$ investigaram a prevalência dos potenciais fatores de risco para pneumonia na população idosa. As seguintes condições foram significativamente mais comuns entre pacientes com pneumonia que entre controles pareados: doença cardíaca $(38,4 \%$ versus $23,0 \%)$, doença pulmonar (13,0\% versus $3,8 \%$ ), asma brônquica (11,9\% versus $3,1 \%)$, terapia imunossupressiva $(2,7 \%$ versus $0,8 \%)$, alcoolismo (2,2\% versus $0,3 \%$ ) e institucionalização $(8,6 \%$ versus $3,9 \%)$. Os fatores de risco independentes para pneumonia foram: alcoolismo (risco relativo $\mathrm{RR}=9,0)$, asma brônquica $(\mathrm{RR}=4,2)$, terapêutica imunossupressiva $(\mathrm{RR}=3,1)$, doença pulmonar $(\mathrm{RR}=3,0)$, doença cardíaca ( $R R=1,9)$, institucionalização $(R R=1,8 \%$ ) e idade (70 anos ou mais versus 60 a 69 anos) $(\mathrm{RR}=1,5)$.

\section{TABAGISMO/DPOC}

Tabagismo é importante fator de risco para PAC, por alterar as defesas locais pulmonares, tais como o clearance mucociliar ${ }^{(13)}$. Outros estudos mostram em tabagistas também alteração no sistema imune e nas funções inflamatórias ${ }^{(14)}$. Tabagismo é o fator de risco mais importante para desenvolvimento da DPOC ${ }^{(14)}$ e ambos, DPOC e tabagismo, são fatores predisponentes para $\mathrm{PAC}^{(15)}$. $\mathrm{Pa}-$ cientes com DPOC grave têm função macrofágica pulmonar prejudicada associada à hipoxia aguda ${ }^{(16)}$, sendo que, no estágio final, também ocorrem alterações na imunidade mediada por células( ${ }^{(7)}$. Estudos longitudinais mostram aumento da mortalidade por pneumonia nos fumantes, sendo que o aumento do risco está associado com o número de cigarros fumados por dia e com o tempo total do hábito de fumar (17). Tabagistas de mais de 20 cigarros por dia têm risco três vezes maior de adquirir pneumonia do que os que nunca fumaram, não havendo diferença de risco usando cigarros de filtro ou com diferentes profundidades de inalação(18).

Almirall et al. ${ }^{(18)}$, examinando o efeito da suspensão do fumo, encontraram redução de aproximadamente 50\% no risco de PAC em ex-tabagistas após cinco anos de abstinência. Esses mesmos autores sugeriram que aproximadamente um em cada três pneumonias em adultos poderia ser evitada se ninguém da população fumasse. Eles calcularam que a proporção de casos de PAC atribuíveis ao tabagismo, sem a ação da DPOC, seria de $23 \%$. Tabagistas têm mais freqüentemente pneumonia causada por C. pneumoniae e Legionella sp. Comorbidade pulmonar está associada significativamente com PAC devida a $S$. pneumoniae e infecções mistas, predispondo também a PAC causada por $P$. aeruginosa e bacilos gram-negativos entéricos ${ }^{(13)}$. Esta associação deve-se provavelmente à colonização traqueobrônquica prévia na DPOC e/ou bronquiectasia $^{(16)}$. 


\section{INSUFICIÊNCIA CARDÍACA}

A doença cardíaca tem grande impacto de saúde pública, por ser comum entre os idosos e aumentar o risco de contrair pneumonia cerca de duas vezes, também aumentando o risco de morte relacionado à mesma ${ }^{(11)}$. Pneumonia está freqüentemente associada à insuficiência cardía$\mathrm{ca}$, sendo que aumento do fluido alveolar pulmonar e alterações nos mecanismos de defesa locais levam a este risco aumentado ${ }^{(19)}$. Koivula et al..$^{(11)}$ mostraram que mesmo o indivíduo com insuficiência cardíaca compensada, sem congestão, apresenta aumento do risco de contrair pneumonia, de ser hospitalizado e de morrer devido a ela.

\section{COLONIZAÇÃO DA OROFARINGE}

Colonização da orofaringe é um degrau inicial importante na patogênese de muitas pneumonias, inclusive na $\mathrm{PAC}^{(20)}$. A má higiene oral está associada ao aumento da flora anaeróbica. Pacientes saudáveis raramente são colonizados na orofaringe por bacilos gram-negativos aeróbicos, sugerindo clearance da orofaringe eficaz em população saudável predisposta à aquisição destas bactérias. Aparentemente, a mucosa da orofaringe em indivíduos saudáveis não é receptiva à adesão dos bacilos gram-negativos aeróbicos, resultando em rápida eliminação dos $\operatorname{mesmos}^{(21)}$

Pacientes idosos apresentam alterações nas barreiras de defesa das mucosas, tornando-os mais suscetiveis à colonização da orofaringe ${ }^{(22)}$. O paciente idoso aumenta a taxa de colonização da orofaringe por patógenos como Staphylococcus aureus e bacilos gram-negativos aeróbicos (como Klebsiella pneumoniae e Escherichia coli). Bacilos gram-negativos colonizam a orofaringe de idosos na freqüência de 19 a 60\%, dependendo se os mesmos residem em suas casas ou em instituições ${ }^{(23)}$. Isso pode ser transitório, com duração menor que três semanas, mas pode, neste período, levar a aumento do risco de pneumonia causada por estes patógenos. Não se sabe qual o defeito nas defesas do hospedeiro que predispõe a essa colonização. A presença de doença respiratória e o fato de estar acamado são fatores de risco para colonização de orofaringe por bacilos gram-negativos. Valenti et al. ${ }^{(23)}$ descreveram que a incidência de colonização por bacilos gram-negativos aumenta com debilidade e doença crônica, assim como com uso de sonda nasogástrica. Esses autores mostraram que a colonização ocorre particularmente no paciente que não pode deambular sem assistência, que tem dificuldade em realizar suas atividades diárias ou tem incontinência urinária, doença cardíaca, doença respiratória crônica ou estado clínico deteriorado.

PAC por bacilos gram-negativos entéricos é mais comum em países em desenvolvimento que em países industrializados. Wolf et al. (24) investigaram a flora nasofaríngea de crianças saudáveis com menos de cinco anos em Angola, Brasil e Holanda, para verificar se bacilos gram-negativos entéricos são mais freqüentemente parte da flora comensal em países em desenvolvimento. Foram excluídas as crianças que recebiam antibióticos e estavam malnutridas. As crianças brasileiras e angolanas tinham maior número de pessoas vivendo na mesma casa que as crianças holandesas (5,7 e 7 versus 3,9, respectivamente). Bacilos gram-negativos entéricos foram muito mais prevalentes nas crianças brasileiras $(50 \%)$ e angolanas (57\%) que nas holandesas (4\%). Assim, ser portador de bacilos gram-negativos entéricos está associado com o número de dependentes vivendo no mesmo domicílio. A alta taxa de portadores de bacilos gram-negativos entéricos em crianças de Angola e do Brasil pode explicar por que estes bacilos são causa comum de pneumonia em países em desenvolvimento. Portanto, a sua prevenção está relacionada à melhoria das condições socioeconômicas desta população.

\section{MiCRO E MACROASPIRAÇÃO}

Tracy et al. ${ }^{(25)}$ estudaram os efeitos da idade sobre a deglutição orofaríngea em indivíduos normais, sem história de dano estrutural de cabeça ou pescoço, alteração neurológica, desordens gastrintestinais ou disfagia. Os resultados sugerem que a deglutição orofaríngea altera-se com a idade avançada, provavelmente por aumento do tempo de processamento neural e diminuição do controle oral. Assim, o envelhecimento per se pode ser causa de disfunção orofaríngea. Juntamente com o aumento da carga de microorganismos presentes na orofaringe, a aspiração torna-se um perigo maior nos pacientes idosos.

Quando ocorre colonização do trato respiratório superior, aspiração de secreções da orofaringe é o meio pelo qual o trato respiratório inferior é inoculado, representando o degrau inicial na maioria das infecções respiratórias inferiores. Aspiração de pequena quantidade de secreção orofaríngea ocorre em aproximadamente $50 \%$ dos hospedeiros normais enquanto dormem ${ }^{(26)}$, provavelmente com maior freqüência quando há alteração do sensório, uso de álcool ou de drogas sedativas. Como a concentração bacteriana das secreções da orofaringe é muito alta, na ordem de $10^{8-10}$ organismos por $\mathrm{ml}$, a aspiração de pequena quantidade $(0,01 \mathrm{a} 0,1 \mathrm{ml})$ pode dar um grande inócuo bacteriano para o pulmão, iniciando a pneumonia.

Alguns dos fatores que predispõem à aspiração incluem: disfunção peristáltica esofágica; disfagia associada a carcinoma ou outra doença esofágica que altere a motilidade do esôfago, como esclerodermia, poliomiosite e megaesôfago; reflexo da tosse ineficaz; alteração do nivel de consciência (letargia) por doença do sistema nervoso central (por ex.: convulsões) ou medicamentos sedativos; $e$ tubos endotraqueais ou nasogástricos que alteram as barreiras mecânicas normais ${ }^{(20)}$. Pacientes com acidente vas- 
cular cerebral (AVC) e outras doenças neurológicas, que reduzem o nivel de consciência ou alteram a motilidade do esôfago, podem ter afetado seu mecanismo de deglutição. Sasaki et al.(27), estudando o reflexo da deglutição durante o dia $e$ a noite em indivíduos com doença cerebrovascular e controles saudáveis, concluíram que durante a noite há importante fator de risco para o desenvolvimento de pneumonia por aspiração no idoso com doença cerebrovascular. Nilsson et al. ${ }^{(28)}$, estudando 100 pacientes com AVC, verificaram que após seis meses do episódio agudo, sete deles ainda persistiam com disfagia, levando a aumento do risco de pneumonia.

Kikuchi et al. (29) investigaram a contribuição da aspiração silenciosa durante o sono na PAC em pacientes idosos. Mostraram que $71 \%$ dos idosos com episódios de pneumonia tinham aspirado, o que somente ocorreu em $10 \%$ dos indivíduos controles pareados por idade. Esses resultados podem indicar um importante papel da aspiração silenciosa no desenvolvimento da PAC no idoso. Esses achados mostram que a aspiração silenciosa ocorre mais freqüentemente em pacientes idosos e que mesmo idosos saudáveis podem não ser capazes de clarear essas secreções tão eficazmente quanto indivíduos mais jovens.

\section{AlCOOlismo/CIRROSE HEPÁTICA}

Embora seja difícil distinguir dos efeitos de outras comorbidades, o álcool parece ser um fator de risco para o desenvolvimento da pneumonia(30). Ruiz et al. ${ }^{(31)}$ encontraram o alcoolismo (definido como ingestão de álcool maior ou igual a $80 \mathrm{~g}$ ) como único fator de risco independente para PAC grave. Esses autores não identificaram como fatores de risco nem o tempo de uso do álcool nem a história de alcoolismo, sugerindo que os efeitos agudos do consumo do álcool são mais importantes para o desenvolvimento da pneumonia. O abuso do álcool está associado com aumento da freqüência de pneumonias que vão à UTI, aumento do tempo de permanência hospitalar e aumento do custo hospitalar(30).

O álcool afeta adversamente os sistemas respiratório e imune ${ }^{(1,26)}$. O abuso do álcool é associado com: aumento da colonização da cavidade oral por flora gram-negativa; alteração do mecanismo de clearance respiratório, incluindo depressão dos reflexos glótico e da tosse, assim como da ação ciliar; risco de alteração da consciência e de convulsões; e vômitos com aspiração(26). O número de granulócitos e linfócitos pode estar diminuído com o álcool, sendo que a função dos granulócitos está adversamente afetada por exposição ao álcool, com alteração do número de neutrófilos recrutados no sítio da infecção(1).

Uso excessivo de álcool e comorbidade hepática estão significativamente associados com PAC devida a S. pneumoniae e infecções mistas, sendo o abuso alcoólico associado com bacteremia devida particularmente ao $S$. pneu- moniae. Infecções devidas a bactérias atípicas, especialmente $C$. pneumoniae, também são mais freqüentes nesses pacientes ${ }^{(13)}$.

\section{DEFICIÊNCIA NUTRICIONAL}

O papel dos fatores nutricionais como fator de risco da PAC ainda não está bem definido. Em revisão sobre nutrição e imunidade, Chandra ${ }^{(32)}$ concluiu que, em certos estados de deficiência relacionados com má nutrição, ocorre diminuição da resposta dos mitógenos e antígenos, das células $\mathrm{CD}_{4}+$, da taxa $\mathrm{CD}_{4} / \mathrm{CD}_{8}$, da IgA secretória e dos neutrófilos killing. Fletcher et al. ${ }^{(33)}$ encontraram associação entre albumina sérica baixa, índice de massa corporal e área muscular do braço com diminuição da hipersensibilidade tardia.

Infecções respiratórias agudas são a principal causa de morte na infância em países em desenvolvimento. Victora et al. ${ }^{(34)}$, em revisão comissionada pela Organização Mundial de Saúde, examinaram as relações entre pneumonia e fatores nutricionais, estimando o efeito potencial das intervenções nutricionais. Baixo peso ao nascer, má nutrição (avaliada por antropometria) e falta de amamentação no peito parecem ser importantes fatores de risco para pneumonia na infância, sendo que intervenções nutricionais podem ter efeito importante, reduzindo as mortes por pneumonia. Na América Latina, promoção da amamentação materna teve efeito similar à melhora do peso ao nascer, enquanto intervenções para prevenir má nutrição tiveram menor efeito. Nas outras regiões estudadas, intervenções para prevenir má nutrição e baixo peso ao nascer foram mais promissoras que a promoção da amamentação materna.

Há também maior morbidade e mortalidade por doenças respiratórias nos pacientes idosos pobres, que não possuem casa adequada, são portadores de má nutrição crônica e têm menor acesso aos cuidados de saúde ${ }^{(35)}$. Uma grande parte dos idosos institucionalizados tem níveis circulantes baixos de vitaminas, particularmente cianocobalamina, folato e piridoxina ${ }^{(36)}$. A administração de zinco pode corrigir alguns dos declínios na resposta imune relacionados com a idade ${ }^{(37)}$. Assim, é possivel que a propensão à infecção no idoso possa estar relacionada, pelo menos em parte, à menor concentração dessas vitaminas ou de zinco teciduais. Deficiências de outras vitaminas, minerais e nutrientes podem também ser importantes, mas poucos estudos foram feitos para examinar sua contribuição.

\section{IMUNOSSUPRESSÃO}

PAC pode surgir primariamente em indivíduos previamente saudáveis, como também como secundária a uma ou mais comorbidades predisponentes. Comorbidades, em termos de condições imunossupressivas, abrangem doenças com alguma imunodisfunção local ou sistêmica (como 
DPOC ou diabetes mellitus) e aquelas associadas com imunodepleção grave (como infecção por HIV e síndrome da imunodeficiência adquirida - AIDS e pacientes transplantados ou neutropênicos).

Corticóide em dose diária igual ou maior que $10 \mathrm{mg}$, ou dose total cumulativa de $700 \mathrm{mg}$ de prednisolona-equivalente, tem sido associado com significativo risco de infecção oportunística ${ }^{(38)}$. Tratamento com corticóide na dose maior que $20 \mathrm{mg} /$ dia está associado mais freqüentemente com PAC grave. Este achado sugere que mesmo baixas doses de corticóide têm efeito imunossupressor, favorecendo a infecção pulmonar grave, independente da doença de base, não suportando a hipótese de que tratamento preexistente com baixas doses de corticóide poderia modificar favoravelmente a resposta inflamatória ${ }^{(31)}$.

\section{FATORES AMBIENTAIS}

Os primeiros estudos em nosso meio a respeito dos efeitos deletérios da poluição sobre o aparelho respiratório foram realizados no Laboratório de Poluição Atmosférica Experimental da Faculdade de Medicina da Universidade de São Paulo(39). Os efeitos das condições atmosféricas da região central da cidade de São Paulo sobre o aparelho respiratório foram avaliados com o seguinte experimento: ratos foram mantidos, por períodos de seis meses e um ano, no centro de São Paulo, sendo comparados com animais controles, alojados pelo mesmo período de tempo em local com atmosfera "limpa". Os resultados demonstraram que os altos niveis de poluição urbana foram responsáveis por lesões de natureza inflamatória nas vias aéreas dos ratos que ficaram aclimatados em São Paulo(40). Após, foi realizado um estudo em 100 pulmões de cadáveres necropsiados por morte violenta, sem antecedentes de doença pulmonar ou doenças sistêmicas prévias. Foram escolhidas duas cidades representativas do Estado de São Paulo, de acordo com o Relatório de Qualidade de Ar da Cetesb: Guarulhos (altos níveis de poluição) e Ribeirão Preto (baixos índices de poluição). Foram constatadas, naqueles procedentes de Guarulhos, as mesmas alterações de natureza inflamatória encontradas nos ratos ao longo das vias aéreas proximais e distais ${ }^{(41)}$.

O paciente idoso tem maior número de hospitalizações por doença respiratória quando aumenta a quantidade de ozônio na atmosfera, sendo este um significante e independente fator de risco para admissão hospitalar por pneumonia ${ }^{(42)}$. A grande amplitude térmica diária, assim como a elevada umidade relativa do ar, também predispõem à pneumonia ${ }^{(43)}$.

\section{VACINAÇÕES}

As vacinações contra influenza e pneumococos podem diminuir a gravidade da doença e morte por gripe e pneu- monia, que ocorrem freqüentemente em pacientes com doenças crônicas ${ }^{(44)}$.

A seguir, revisaremos separadamente as vacinações antiinfluenza e antipneumocócica.

\section{VACINAÇÃO ANTIINFLUENZA}

A influenza é uma virose respiratória aguda que ocorre esporadicamente durante todo ano. Geralmente, manifesta-se sob forma de surtos e epidemias. A transmissão da gripe dá-se pelo contato com pessoas gripadas, por meio do ar ou da saliva. É considerada uma doença de alta transmissibilidade, principalmente em ambientes fechados. O termo influenza, do latim del fredo (frio), relaciona a doença com o inverno. Já o termo gripe tem sua origem no russo khripu, que quer dizer rouquidão.

$\mathrm{O}$ vírus da influenza pertence à família Orthomyxoviridae e apresenta três tipos antigênicos: $\mathrm{A}, \mathrm{B}$ e $\mathrm{C}^{(6)}$. Os vírus tipo A são subdivididos com base em seus dois antígenos de superfície, a hemaglutinina $(\mathrm{H})$ e a neuraminidase $(\mathrm{N})$. As três cepas do vírus da influenza tipo A que freqüentemente afetam os seres humanos são: H1N1, H2N2 e H3N2. Durante 1997 e 1998, outro tipo antigênico do vírus da influenza A (H5N1) foi isolado de humanos em Hong Kong, sendo originado em aves (galinhas) ${ }^{(5)}$.

Os vírus da influenza apresentam variação significante em suas proteínas de superfície. A infecção ou a vacinação com um subtipo do vírus proporciona pequena ou nenhuma proteção contra subtipo diferente, não sendo possivel, desta forma, ser obtida imunidade prolongada. Os vírus da influenza $\mathrm{B}$ apresentam maior estabilidade antigênica do que os vírus da influenza $\mathrm{A}$, embora também possa ocorrer variação nos mesmos, acarretando epidemias importantes de gripe. As pandemias causadas pelo vírus da influenza ocorrem de forma imprevisível, como conseqüência de modificação genética, aproximadamente a cada 10-40 anos, afetando até $50 \%$ da comunidade. A pandemia de "gripe espanhola" (A/H1N1), em 1918, o pior surto de influenza deste século, levou ao óbito uma estimativa de 20 milhões de indivíduos em todo o mun$\mathrm{do}^{(45)}$. Nos Estados Unidos, estima-se que cerca de 150 mil pessoas, em média, são internadas todo ano em decorrência de complicações associadas à influenza, a maioria delas com mais de 65 anos $^{(6)}$. A mortalidade naquele país associada a cada uma das pandemias recentes, de 1957 [A/Ásia (H2N2)] e de 1968 [A/Hong Kong (H3N2)], tem sido estimada como sendo de mais de 100.000 pessoas por período pandêmico. O surto recente da nova cepa do vírus da influenza H5N1, em Hong Kong, demonstra a contínua ameaça de uma nova pandemia(46,47).

Podem ocorrer dois tipos de variação no vírus da influenza. A mutação antigênica menor (drift) é dada pelo acúmulo estável de mutações que acarretam alterações 
dos aminoácidos nos locais antigênicos das proteínas, a hemaglutinina e/ou a neuraminidase. Essas alterações reduzem a ligação aos anticorpos, reduzindo subseqüentemente a imunidade preexistente do hospedeiro e facilitando a disseminação da influenza. A mutação antigênica maior (shift) é uma alteração dramática abrupta, ocorrendo na superfície das proteínas hemaglutinina e/ou neuraminidase, em decorrência das substituições de todo o segmento gênico viral por outro segmento de um vírus da influenza de animal (por ex.: aviário). Visto que a população apresenta pequena ou nenhuma imunidade para essas novas cepas, elas ocasionam pandemias associadas com morbidade e mortalidade inusitadamente elevadas. Além da drift e da shift antigênica, o reaparecimento de uma cepa antiga do vírus é uma causa potencial de sur$\operatorname{tos}^{(5)}$.

A prevenção da influenza ou a redução de sua gravidade é direcionada para a administração da vacina inativada, que é dada seis a oito semanas antes do início da estação sazonal da influenza. A vacina é administrada através da via intramuscular, devendo ser aplicada anualmente. De acordo com a FUNASA, a influenza tem maior prevalência no período de março a agosto, quando ocorre maior circulação do vírus ${ }^{(6)}$. Como outros vírus podem causar a gripe, a proteção conferida pela vacina está relacionada apenas aos tipos (cepas) dos vírus que a compõem. As características das cepas atualmente em atividade formam a base para a escolha daquelas cepas a serem incluídas em cada vacina anual para a influenza. São essas mutações dos vírus da gripe que induzem mudanças na composição da vacina a cada ano, baseadas em recolhimento do vírus em nível mundial no ano precedente ${ }^{(48)}$. No Brasil, esse processo de coleta e envio é realizado por três laboratórios de referência: Adolfo Lutz (SP), Fiocruz (RJ) e Evandro Chagas (PA). Um estudo multicêntrico vem sendo realizado em cinco capitais do País, com o intuito de implementar a coleta de material para melhor identificação do vírus ${ }^{(31)}$. A vacina por vírus inativado (morto) contém três cepas (duas do vírus da influenza A e uma do da influenza B), representando aquelas mais prováveis de circular no Hemisfério Sul durante o próximo inverno. Para o ano 2000, a Organização Mundial de Saúde (OMS) recomendou que as cepas a serem incluídas na vacina usada no Hemisfério Sul fossem: A/Sydney/5/97 (H3N2), A/New Caledonia/20/99 (H1N1) e B/Beijing/184/93.

Além do grau de similaridade entre as cepas dos vírus contidos na vacina e as cepas circulando na comunidade, o sucesso da vacina depende também da idade e do sistema imunológico do paciente. Embora a influenza acometa mais freqüentemente crianças e adolescentes, a taxa de morbidade e mortalidade é maior nos pacientes idosos, sendo o vírus da influenza A o responsável habitual pelas epidemias, pandemias e mortes neste grupo ${ }^{(49)}$. É questionável se a idade é um fator de risco independente. Nguyen-Van-Tam e Nicholson ${ }^{(49)}$, revisando os prontuários de pacientes que morreram por influenza durante a epidemia ocorrida na Inglaterra em 1989-1990 (influenza H3N2), mostraram que 93\% deles apresentavam uma ou mais doenças crônicas subjacentes. Nichol et al. ${ }^{(50)}$ notaram que a vacina é altamente eficaz em adultos jovens (70-90\% em adultos com idade inferior a 60 anos), ainda alcançando eficácia de 60 a $70 \%$ nos pacientes idosos, parecendo ter menor efeito demonstrável naqueles com doenças de base. Outros estudos mostram que ela é eficaz em adultos trabalhando na área de saúde, em idosos vivendo na comunidade, como também em idosos com doenças médicas crônicass ${ }^{(51)}$. Estudos realizados nos países onde foi implantada têm mostrado que a vacina contra influenza pode reduzir em até $70 \%$ a necessidade de hospitalização e em até $80 \%$ o risco da ocorrência de óbitos entre as pessoas idosas ${ }^{(6)}$.

Nichol e Goodman ${ }^{(52)}$ encontraram redução nas hospitalizações por pneumonia e influenza nos idosos entre 65 e 74 anos, sejam saudáveis ou com alguma comorbidade, embora os resultados não alcançassem significância estatística entre os idosos saudáveis. Como a vacinação foi associada a significante economia e redução no risco de morte em ambos os grupos, os autores concluíram que a vacina contra influenza nos idosos de 65 a 74 anos, tanto saudáveis como com risco aumentado, é associada a substancial benefício para a saúde. Entretanto, Remarque(53) mostrou que a indução de anticorpos com a vacina antiinfluenza não é sempre ótima nos idosos, podendo esta menor eficácia ser devida a fatores múltiplos, que incluem estado de saúde e exposição prévia ao vírus da influenza. Nichol et al. ${ }^{(54)}$ notaram que, em pacientes idosos com doença pulmonar crônica, a influenza é associada a significantes efeitos adversos à saúde, sendo a vacinação antiinfluenza acompanhada de substanciais benefícios, incluindo diminuição das hospitalizações e das mortes.

Atualmente, há fortes evidências de que a vacinação antiinfluenza protege pacientes de alto risco da hospitalização e morte por influenza ${ }^{(6)}$. Possivelmente, a maior evidência da eficácia da vacina antiinfluenza venha da Holanda, onde, em 1991-1992, foi conseguida permissão ética para realizar trabalho controlado, randomizado, duplo-cego, com evidência sorológica da vacina em pacientes idosos ${ }^{(55)}$. Os resultados mostraram que a vacina reduz em $50 \%$ a incidência de influenza, parecendo ser esta proteção maior em pacientes com história de imunização anual repetida e entre aqueles com condições de base de alto risco. Assim, é razoável concluir que a vacina contra a influenza, dada a pacientes de alto risco, substancialmente reduz a possibilidade de morte e hospitalização durante períodos de epidemia. Assim, a vacina deve ser usada nos indivíduos idosos, principalmente naqueles 
portadores de doenças crônico-degenerativas e/ou residentes em instituições. Os profissionais (médicos, enfermeiros, fisioterapeutas, assistentes sociais, etc.) que têm contato direto com idosos em instituições, hospitais ou em visitas domiciliares, também devem ser vacinados(56). Quando as cepas vacinais epidêmicas são adequadamente pareadas, as elevadas percentagens de vacinação em casas de saúde e outros ambientes de atendimento crônico induzem imunidade global e podem reduzir o risco de surtos.

A vacina também é eficaz na população mais jovem. Desde que a transmissão na comunidade pode ser interrompida pela vacinação das crianças em idade escolar, este grupo também deve ser vacinado(57). Ahmed et al. ${ }^{(58)}$ mostraram que a vacina antiinfluenza reduziu as admissões hospitalares por influenza, pneumonia, bronquite $e$ enfizema em pacientes com 16 anos ou mais. Neuzil et al. ${ }^{(59)}$ observaram, estudando a eficácia da vacina para influenza em mulheres com menos de 65 anos, que certas condições médicas crônicas levam à morbidade e mortalidade substancial por eventos cardiopulmonares agudos durante os surtos de influenza. Há aumento da mortalidade e maior incidência de pneumonia bacteriana $e$ cetoacidose em pacientes diabéticos durante epidemias de influenza(60). Nestes pacientes, Colquhoun et al. ${ }^{(61)}$ en- contraram redução de $79 \%$ na hospitalização com o uso da vacina antiinfluenza no período imediatamente precedendo as epidemias. Assim, é também necessário imunizar anualmente com a vacina antiinfluenza esta população. As principais indicações para a vacinação antiinfluenza estão no Quadro 4.

As reações adversas à vacina, que são dor local, febre e cefaléia, são discretas ${ }^{(62)}$. A vacinação é segura, com somente relatos ocasionais de anafilaxia. Na epidemia de 1976-1977, nos Estados Unidos, foi relatada a possibilidade de que a vacina pudesse ter sido fator desencadeante da síndrome de Guillain-Barré, associação esta não comprovada em estudos posteriores ${ }^{(63)}$. As contra-indicações à utilização da vacina são doença febril aguda grave, alergia às proteínas do ovo e alergia a outros componentes da vacina (timerosal e neomicina). A administração simultânea das vacinas antiinfluenza e antipneumocócica não aumenta a incidência de reações indesejáveis ${ }^{(56)}$.

A influenza é o melhor modelo conhecido para o estudo da co-infecção bacteriano-viral. Epidemias de influenza resultam em aumento na taxa de admissão hospitalar por pneumonia bacteriana causada por pneumococos, Haemophilus influenzae e Staphylococcus aureus. Similarmente, maior incidência de doença meningocócica, particularmente com formas graves, segue surtos de in-

QUADRO 4

Indicações para o uso da vacina antiinfluenza*

1. Idade igual ou superior a 60 anos

2. Doenças crônicas

- Doença pulmonar (DPOC, tuberculose, asma)

- Doença cardíaca (reumática, isquêmica)

- Diabetes mellitus

- Disfunção renal (nefrite crônica, síndrome nefrótica)

- Doença hepática (cirrose)

- Doenças neurológicas (AVC, doença de Parkinson, esclerose múltipla)

- Shunt do fluido cérebro-espinhal

3. Imunossupressão

- Infecção por HIV

- Terapia imunossupressora (inclusive corticóides)

- Pós-transplante de órgãos (inclusive de medula óssea)

- Neoplasma maligno (inclusive hematogênico)

- Alcoolismo

- Disfunção esplênica ou asplenia (inclusive anemia falciforme)

4. Indicações adicionais

- Condições sociais/ambientais (asilados, índios)

- Agentes de saúde e pessoal de saúde

- Cuidadores de pacientes de alto risco (inclusive domiciliarmente)

- Mulheres grávidas com condições de alto risco que estarão no $2^{\circ}$ ou $3^{\circ}$ trimestre de gravidez durante a epidemia de influenza

- Crianças e adolescentes recebendo terapia com AAS por longo tempo

* Referência: 105 
fluenza com intervalo de duas semanas. Embora o mecanismo preciso não seja conhecido, parece estar envolvida a depressão da atividade bactericida dos fagócitos do hospedeiro pelo vírus da influenza. Co-infecção bacteriano-viral não é justificativa para a prescrição de antibióticos sistêmicos na doença viral (64).

Várias doenças virais serão melhor prevenidas através da imunização, encorajando o desenvolvimento de vacinas virais e campanhas de imunização. Novas abordagens da vacinação, tais como o desenvolvimento de vacinas a partir de vírus vivo para administração intranasal, podem melhorar o controle da influenza no futuro ${ }^{(65)}$.

\section{VACINA ANTIPNEUMOCÓCICA}

A vacinação contra a doença pneumocócica tem longa história, que começou com uma vacina feita há quase 80 anos, desenvolvendo-se através da descoberta dos tipos de pneumococos. Isto levou à imunização passiva como forma de tratamento a partir dos anos $30^{(66)}$. A vacina pneumocócica que é utilizada atualmente tem mostrado sucesso, sendo eficaz em prevenir infecções pneumocócicas invasivas em pacientes imunocompetentes. Contém antígenos capsulares purificados (polissacarídeos) de 23 dos mais de 80 tipos diferentes de $S$. pneumoniae $(1,2$, $3,4,5,6 \mathrm{~B}, 7 \mathrm{~F}, 8,9 \mathrm{~N}, 9 \mathrm{U}, 10,11 \mathrm{~A}, 12 \mathrm{~F}, 14,15 \mathrm{~B}, 17 \mathrm{~F}$, 18C, 19A, 19F, 20, 22F, 23F, 33F). O antígeno polissacarídeo induz anticorpo tipo-específico que aumenta a opsonização, fagocitose e destruição dos pneumococos pelas células fagocíticas ${ }^{(67)}$.

Os tipos componentes da vacina cobrem cerca de $85 \%$ dos sorotipos causadores de pneumonia e de doença pneumocócica invasiva na comunidade ${ }^{(68)}$. Estes 23 sorotipos estão freqüentemente associados com bacteremia, sendo responsáveis por aproximadamente $80 \%$ das infecções que ocorrem no paciente idoso. Os seis sorotipos associados com mais de $85 \%$ da doença pneumocócica invasiva resistente à penicilina nos Estados Unidos e Reino Unido ou foram incluídas na vacina ou estimulam a imunidade cruzada ${ }^{(69)}$. Em Israel, foram identificados 24 sorogrupos em 398 amostras de pneumococos provenientes de pacientes adultos hospitalizados com pneumonia pneumocócica. Destes 24 sorogrupos, somente 13 estão incluídos na vacina pneumocócica, sendo que estes 13 sorotipos perfizeram $94 \%$ de todos os pneumococos iso$\operatorname{lados}^{(70)}$.

A vacina é altamente purificada, contendo 25 microgramas de cada um dos 23 sorotipos de pneumococos, englobados no volume de $0,5 \mathrm{ml}$ para injeção intramuscular ou subcutânea. Pode ser administrada simultaneamente com a vacina antiinfluenza, em sítios diferentes. Reações leves à vacinação são comuns. Riley et al. ${ }^{(71)}$ relataram eritema leve e enduração no sítio da injeção em $27 \%$ dos pacientes, com febre em grau baixo em $7 \%$, não haven- do reações sérias. Deve-se retardar a imunização, se possivel, em casos de febre, doença aguda e recaída de doença crônica até sua recuperação. Há somente relatos ocasionais de anafilaxia. Contra-indicações ao uso da vacina incluem hipersensibilidade pregressa ou história de alergia aos componentes da mesma, doença respiratória ou infecção aguda, gravidez e crianças menores de dois anos de idade (a resposta sorológica adequada só ocorre naquelas com idade superior a dois anos). A vacina deve ser aplicada pelo menos duas semanas antes da esplenectomia. O intervalo entre o uso da vacina e de terapia imunossupressora deve ser o mais longo possivel(72).

A incidência da pneumonia pneumocócica bacteriêmica tem aumentado, sendo que, na Suécia, este aumento foi substancial na última década ${ }^{(73)}$. Estudos recentes sugerem que a vacina traz economia de custos nos países desenvolvidos em termos de prevenção da bacteremia ${ }^{(74)}$. A eficácia da vacina pneumocócica é de cerca de $90 \%$ em prevenir bacteremia pneumocócica e pneumonia pneumocócica em adultos jovens sem outra doença ${ }^{(75)}$. Fatores influenciando a eficácia da vacina incluem idade do indivíduo, o estado de sua resposta imune, a presença ou ausência de doença médica básica e o nível de anticorpos pneumocócicos obtidos. A vacina pneumocócica parece ser mais eficaz em pessoas saudáveis, ainda havendo controvérsia acerca da eficácia da vacina nos idosos e naqueles com comorbidades ${ }^{(76)}$. Fine et al. ${ }^{(77)}$ concluíram, em metanálise, que a vacina pneumocócica oferece proteção de cerca de $66 \%$ contra pneumonia pneumocócica em pacientes normais e de baixo risco, mas não em pacientes de alto risco (aqueles com condições médicas crônicas ou doenças imunossupressoras).

A doença pneumocócica invasiva está associada com elevada mortalidade no paciente idoso. Embora a vacina pneumocócica provavelmente dê somente proteção limitada contra pneumonia pneumocócica no idoso, ela fornece aproximadamente $50-80 \%$ de proteção contra doença pneumocócica invasiva ${ }^{(78)}$. Assim, a vacinação antipneumocócica deve ser recomendada para todos os pacientes idosos, embora sua eficácia possa ser menor nos mesmos, assim como nos indivíduos com algumas das categorias de alto risco ${ }^{(28)}$. Na Alemanha, desde 1998, a STIKO recomenda que a vacinação pneumocócica seja efetuada em todos os indivíduos a partir dos 60 anos, assim como nas crianças, adolescentes e adultos com alto risco devido à doença primária. Assim, a vacina é recomendada para todos os indivíduos idosos, sendo particularmente indicada: naqueles institucionalizados, nos quais é maior a incidência dessa infecção; nos portadores de doenças crônicas, como diabetes mellitus, doença pulmonar obstrutiva crônica, insuficiência cardíaca, cirrose hepática; $e$ naqueles com infecções recorrentes ${ }^{(79,80)}$. A vacina também é indicada para os pacientes esplenectomizados ${ }^{(80)}$, 
assim como aqueles considerados em risco, particularmente adultos jovens que recentemente começaram a beber grandes quantidades de álcool ou tiveram o diagnóstico de diabetes mellitus ${ }^{(81)}$. Vacinação contra o S. pneumoniae também é recomendada para pacientes imunossuprimidos, incluindo aqueles com insuficiência renal crônica, síndrome nefrótica e transplantados renais. As principais indicações da vacinação antipneumocócica estão no Quadro 5.

Kazancioglu et al. ${ }^{(82)}$, estudando prospectivamente 21 pacientes com transplante renal funcionante, observaram que a vacinação pneumocócica não provocou efeitos adversos sistêmicos ou locais. A mesma foi eficaz, levando a aumento significativo dos títulos de anticorpos seis e 12 semanas após a vacinação, em todos os pacientes exceto um.

Diabetes também é fator de risco para bacteremia em pacientes com pneumonia pneumocócica, levando a aumento da mortalidade. Pacientes diabéticos têm resposta normal à vacinação pneumocócica, que se mostra eficaz na prevenção da pneumonia ${ }^{(83)}$. Nos pacientes com diabetes mellitus, a vacinação é importante intervenção de saúde pública para reduzir a mortalidade e morbidade por influenza e pneumonia.

Singer e McCune ${ }^{(84)}$ recomendam imunização específica nos pacientes com doenças reumáticas, especialmente naqueles em uso de drogas imunossupressoras. Santamauro e White ${ }^{(85)}$ relataram sucesso encorajador vacinando contra organismos encapsulados pacientes portadores de doença de Hodgkin. Segundo Arunabh e Niederman ${ }^{(86)}$, a vacina é mais eficaz quando administrada na fase precoce do curso de uma doença crônica.

Guerrero et al. ${ }^{(87)}$, revendo os dados de 2.000 pacientes infectados por HIV, concluíram que a imunização pneumocócica foi associada com diminuição de cerca de $70 \%$ no risco de pneumonia. Este efeito foi observado mesmo quando a imunização foi feita naqueles com contagem de $\mathrm{CD}_{4}$ menor que $100 / \mathrm{mm}^{3}$. Gebo et al. ${ }^{(88)}$ relataram que a eficácia da vacina pneumocócica diminuiu nos pacien- tes com HIV e $\mathrm{CD}_{4}$ em número inferior a 200 céls $/ \mathrm{mm}^{3}$. Assim, estes dados suportam a recomendação atual de, o mais precocemente possivel, imunizar com a vacina antipneumocócica todos os indivíduos infectados com o vírus HIV.

A vacina antipneumocócica é aplicada somente uma vez, com algumas exceções. Revacinação com intervalo menor que cinco anos pode causar reações graves ${ }^{(89)}$. Por este motivo, como regra geral, a revacinação não é recomendada, a não ser nos indivíduos de alto risco após seis anos de intervalo(67). Candidatos à revacinação pneumocócica incluem os que apresentam alto risco de infecção pneumocócica fatal: pacientes asplênicos que receberam previamente a vacina com 14 sorotipos, aqueles com declínio acelerado nos títulos de anticorpos, com insuficiência renal, nefrose ou recipientes de transplantes. Os indivíduos com 65 anos ou mais devem ser revacinados se foram vacinados previamente há mais de cinco anos e tinham menos que 65 anos quando receberam a primeira dose ${ }^{(90)}$. Estudos clínicos e sorológicos sugerem que a proteção induzida pela vacina declina após três a cinco anos, levando à preocupação acerca da revacinação de rotina. Porque a vacina polissacarídea pneumocócica não induz memória imunológica, são esperados benefícios da revacinação de curta duração. Deve ser considerada, como estratégia alternativa, a vacinação com uma das novas vacinas protéicas ou com a vacina conjugada pneumocócica seguida por reforço com a vacina polissacarídea. $\mathrm{O}$ uso das vacinas pneumocócicas de nova geração pode dar proteção por toda a vida contra a infecção pneumocócica, sendo que seu uso teria um imenso impacto na saúde pública mundial(78).

$\mathrm{Na}$ literatura, encontram-se resultados controversos sobre a eficácia da vacina antipneumocócica. Ortqvist et al. ${ }^{\left({ }^{1}\right)}$ estudaram, em pacientes idosos e de meia-idade (50 a 85 anos) não imunocomprometidos, a eficácia da vacina pneumocócica polissacarídea na prevenção da pneumonia pneumocócica e da pneumonia como um todo. Concluíram que esta vacina não preveniu a pneumonia

\section{QUADRO 5 \\ Indicações para o uso da vacina antipneumocócica* (Graus de risco em ordem decrescente)}

- Grupo 1 - doença de Hodgkin, mieloma múltiplo, deficiência de imunoglobulina, lúpus eritematoso disseminado, deficiência imunológica induzida por drogas, transplante renal, doença maligna hematológica, carcinoma, infecção por HIV e AIDS

- Grupo 2 - esplenectomia ou disfunção esplênica, anemia falciforme, síndrome nefrótica

- Grupo 3 - diabetes mellitus, doença pulmonar crônica, doença cardíaca crônica, insuficiência renal crônica requerendo diálise, cirrose hepática, alcoolismo

- Grupo 4 - idosos (60 anos ou mais)

Referência: 90 
como um todo, nem a pneumonia pneumocócica, pois $19 \%$ dos pacientes vacinados e $16 \%$ do grupo placebo desenvolveram uma nova pneumonia, diagnosticada como pneumocócica em 5,6\% do grupo vacinado e em $4,5 \%$ do grupo placebo, não surgindo diferença na taxa de morte entre os dois grupos. Entretanto, nesse estudo a idade média dos pacientes foi muito alta, o que pode ter levado os mesmos a responderem menos eficazmente à vacina. Esse estudo também não demonstrou conclusivamente que não haja proteção contra a doença invasiva. Koivula et al. ${ }^{\left({ }^{22)}\right.}$ também relataram que não houve significativa proteção para pneumonia pneumocócica em pacientes idosos com 60 anos ou mais, sendo a eficácia da vacina somente de $15 \%$. Entretanto, em pacientes com fatores médicos de risco para contrair pneumonia, houve eficácia protetora significante de $59 \%$. Concluíram que a vacinação pneumocócica reduz significativamente a incidência de pneumonia em pacientes idosos com alto risco de contrair pneumonia. Como 34\% da população de 60 anos ou mais está nesse grupo de alto risco, sendo difícil organizar vacinação de modo eficiente somente para o mesmo, a melhor estratégia é vacinar todos os idosos.

Mostrando resultados diferentes dos citados anteriormente, Hutchison et al. ${ }^{(93)}$, fazendo uma metanálise com informações de 13 trabalhos randomizados ou quase-randomizados com mais de 65.000 pacientes, concluíram que a vacina pneumocócica reduz em $83 \%$ o risco de infecção sistêmica devida aos tipos de pneumococos incluídos na vacina e em $73 \%$ a infecção sistêmica devida a todos os pneumococos. Esses autores não acharam evidência de que a vacina tenha menor eficácia no idoso, nos institucionalizados ou naqueles com doença crônica. Do mesmo modo, Nichol et al. ${ }^{(94)}$, estudando os benefícios associados à vacinação pneumocócica em idosos com doença pulmonar crônica, observaram que a vacinação esteve associada a menor número de hospitalizações por pneumonia e de mortes, assim como com menores custos médicos. Em adição, uma série de estudos epidemiológicos sugerem que a vacina é 60 a $70 \%$ eficaz em proteger pacientes idosos, podendo ter papel protetor particularmente contra a doença invasiva ${ }^{(69)}$. Dados de quatro estudos de caso-controle, envolvendo principalmente pacientes idosos e de meia-idade tardia, produziram estimativa de eficácia contra a doença invasiva variando de 56 a $81 \%$. Para pacientes com aumento de risco, por apresentarem comorbidades cardíaca ou pulmonar, a estimativa foi de 61 a $77 \%{ }^{(47)}$. Nenhum desses estudos mostrou qualquer proteção para pacientes com alteração da imunidade, exceto naqueles com asplenia anatômica (proteção de $77 \%)^{(95)}$.

Há problema crescente com a resistência betalactâmi$\mathrm{ca}$, surgindo pneumococos multirresistentes em muitos países. O impacto clínico da infecção por $S$. pneumo- niae droga-resistente não está completamente definido, mas relatos sugerem que o prognóstico é ruim em pacientes com meningite pneumocócica droga-resistente. A vacina polissacarídea capsular pneumocócica pode prevenir muitas infecções invasivas droga-resistentes. Se a vacina pneumocócica conjugada conseguir erradicar os portadores, semelhante à ação da vacina conjugada Hib, a vacinação pode ser a maior arma contra a disseminação da infecção pneumocócica resistente a antibióticos ${ }^{(96)}$.

Nos idosos, o pneumococo leva mais freqüentemente à pneumonia, mas em crianças ocorre principalmente otite média e meningite. Entre 481 casos de meningite bacteriana não-meningocócica, $28 \%$ foram causados por $S$. pneumoniae ${ }^{(97)}$. Hueston et al. ${ }^{(98)}$ analisaram o impacto financeiro que a vacinação antipneumocócica provocaria caso fossem vacinados todos os recém-nascidos. A análise foi limitada a casos de meningite e bacteremia devidas a $S$. pneumoniae, pois os dados são escassos ou inconclusivos para otite média e pneumonia. Baseado somente nestas duas doenças, a imunização com vacina pneumocócica poderia salvar 222 vidas por milhão de crianças vacinadas por ano. Análise dos custos diretos (custos projetados da imunização menos economia por diminuição da doença) mostra que o programa de vacinação pneumocócica poderia resultar em economia entre US\$ 0,08 e US\$ 2,42 por criança. Mais pesquisas devem focalizar este aspecto, esperando-se que a vacinação seja introduzida para uso nos recém-nascidos nos próximos anos.

Muitas crianças com infecção sinopulmonar recorrente não conseguem adequada resposta humoral seguindo imunização com antígeno polissacarídeo. Silk et al. ${ }^{(99)} \mathrm{fi}-$ zeram estudo controlado, comparando a resposta da imunização pneumocócica em crianças com infecção recorrente e em grupo controle saudável da mesma idade. Ambos os grupos foram imunizados com a vacina pneumocócica, sendo os títulos de anticorpos medidos antes e após quatro semanas da imunização. Os sorotipos mais imunogênicos foram 3, 4, 7F, 8, 9N e 18C, enquanto os sorotipos $6 \mathrm{~A}$ e 14 foram os menos imunogênicos. Concluíram que a vacina pneumocócica é imunogênica nessa faixa etária, mas que significativa percentagem de crianças com infecção sinopulmonar recorrente falham em produzir anticorpos sorotipo-específicos adequados seguindo a imunização pneumocócica.

Concluindo, as evidências mais recentes são relativamente claras quanto à prevenção da doença invasiva, parecendo razoável inferir que a vacina oferece cerca de $60 \%$ de proteção. Isso se aplica a indivíduos saudáveis, incluindo aqueles com mais de 65 anos e aqueles de todas as idades com condições tais como diabetes mellitus, doença cardíaca e pulmonar crônica, mas provavelmente não naqueles que estão imunocomprometidos. 
Quanto à prevenção da pneumonia isolada, evidência de eficácia da vacina é limitada a adultos saudáveis de baixo risco ${ }^{(47)}$.

Novos conhecimentos sobre as causas e a patogênese das PAC levarão a novas estratégias para prevenir essas doenças. Vacinas novas e melhores, controle ambiental e educação dos médicos e do público possibilitarão que novas armas sejam aplicadas, como a imunização feita nos pacientes hospitalizados ${ }^{(6)}$.

\section{ASSOCIAÇÃO DAS DUAS VACINAS}

Nichol(100) mostrou o benefício aditivo da vacinação contra influenza e pneumococos durante três surtos de influenza em pacientes idosos com doença pulmonar crônica. Nesse período, a vacinação antiinfluenza isolada foi associada com redução de $52 \%$ nas hospitalizações por pneumonia e redução de $70 \%$ nas mortes. Nesse mesmo período, a vacinação antipneumocócica isolada reduziu $27 \%$ das hospitalizações por pneumonia e $34 \%$ das mortes. As duas vacinas conjuntamente demonstraram benefícios aditivos, levando à redução de $63 \%$ nas hospitalizações por pneumonia e de $81 \%$ nas mortes.

Entretanto, resultados diferentes foram obtidos por Honkanen et al. ${ }^{(101)}$. Estes autores estudaram, em idosos na Finlândia, a eficácia da administração simultânea das vacinas antiinfluenza e antipneumococos versus a vacina antiinfluenza isolada na prevenção da pneumonia, pneumonia pneumocócica e bacteremia pneumocócica. Observaram eficácia aditiva da vacina pneumocócica somente nos casos de bacteremia pneumocócica (+60\%). Assim, a vacina polissacarídea pneumocócica não mostrou qualquer proteção adicional para pneumonia não complicada com bacteremia entre os idosos.

\section{AVALIAÇÃO DAS VACINAS}

A vacinação contra $S$. pneumoniae tem sido recomendada por sua eficácia e diminuição dos custos na população idosa e imunocomprometida. O US Public Health Service estabeleceu como ideal a taxa de $60 \%$ de imunização para idosos e pacientes de alto risco(102). Entretanto, nos Estados Unidos, a taxa de imunização conseguida foi somente de $1 / 3$ a $1 / 2$ da estabelecida(94).

Vold Pepper e Owens ${ }^{(103)}$ avaliaram a vacinação pneumocócica no pessoal militar na ativa. A vacinação aumentou a expectativa de vida em 0,03 dia e diminuiu de US\$ 9,88 o custo por pessoa. Vacinação de todos os 575.000 militares na ativa dos Estados Unidos poderia levar à economia de US\$ 5,7 milhões durante o tempo em que estes indivíduos estivessem vivos e em atividade. Baseados nesses resultados, os militares deveriam considerar a imunização com vacina antipneumocócica para todos os membros militares na ativa.
Na primeira Campanha de Vacinação dos Idosos no Brasil, realizada entre os dias 12 e 23 de abril de 1999, foram vacinados 7,8 milhões de idosos. Esta foi a maior campanha já realizada no mundo. Foram distribuídos 8,7 milhões de doses da vacina contra gripe e 1,6 milhão de doses contra doença pneumocócica, estas últimas aplicadas em idosos hospitalizados e residentes em instituições geriátricas. Em todo o país, 25 mil postos aplicaram a vacina antiinfluenza, com o envolvimento de 75 mil pessoas. Cerca de 900 mil doses da vacina foram empregadas na vacinação de índios e de grande parte do pessoal da área de saúde, sendo também entregues aos Centros de Referência para Imunobiológicos Especiais dos Estados. Foram gastos $\mathrm{R} \$ 66,8$ milhões na aquisição das vacinas, agulhas e seringas. Nessa campanha, os idosos também receberam a vacina dupla (tétano e difteria) ${ }^{(6)}$.

\section{DROGAS ANTIVIRAIS}

Entre as drogas antivirais temos: amantadina e rimantadina e, mais recentemente, zanamivir e oseltamivir.

\section{AMANTADINA E RIMANTADINA}

Amantadina e rimantadina (esta última não registrada na Europa) são recomendadas pelo Centers for Disease Control and Prevention (CDC) na profilaxia da infecção por Myxovirus influenzae tipo A, não tendo indicação em infecções por vírus da influenzae $\mathrm{B}$ ou $\mathrm{C}^{(86,104)}$. Nos Estados Unidos, amantadina foi aprovada para profilaxia da infecção da influenza (H2N2) em 1966 e para profilaxia e tratamento em 1976; rimantadina foi aprovada para tratamento e profilaxia da influenza A em 1993. Elas agem inibindo a replicação viral através da inativação do canal iônico da proteína $\mathrm{M}_{2}$ viral. Surge rapidamente resistência a essas drogas in vitro e in vivo, sendo as variantes resistentes do vírus transmissiveis e patogênicas ${ }^{(105)}$.

Recomenda-se que durante epidemia por influenza $\mathrm{A}$, pacientes de alto risco não protegidos recebam a vacina e sejam tratados com amantadina ou rimantadina por duas semanas, enquanto se espera o desenvolvimento dos anticorpos protetores. A indicação da amantadina independe de o paciente ter sido imunizado com a vacina antiinfluenza, já que age por mecanismo de ação diferente, não sendo usada como substituta da vacinação(56). Embora a atividade da amantadina e da rimantadina contra influenza A seja bem conhecida, seu uso é ainda limitado. Esses agentes têm só efeito curativo moderado, sendo mais eficazes na profilaxia. A eficácia da amantadina como profilática foi de $61 \%$ e a da rimantadina de $64 \%$. No tratamento da influenza, amantadina e rimantadina diminuíram significantemente a duração da febre (em 1,00 e $1,27$ dias, respectivamente) $)^{(106)}$. 
A amantadina é utilizada na dose de 50 a 100mg por dia, na profilaxia dos idosos em contato com o portador doente, seja na comunidade ou em instituições. A medicação é mantida até 24 horas após o desaparecimento dos sintomas do portador. Nos pacientes que já desenvolveram a doença, é iniciada na mesma dose até 24 a 48 horas após o início dos sintomas, sendo suspensa após 48 horas da ausência dos mesmos. A tolerância não é boa, sendo sua utilização limitada pelo perfil de efeitos colaterais $^{(107)}$. Os dados sugerem que a rimantadina é melhor tolerada. Os eventos adversos associados com amantadina e rimantadina incluem transtornos do sistema nervoso central e gastrintestinais (náuseas e vômitos). Os efeitos sobre o sistema nervoso central são mais freqüentes com a amantadina (a qual está também registrada para o tratamento da doença de Parkinson) do que com a rimantadina. Em adição, a taxa de descontinuação da amantadina foi significantemente maior do que com a rimantadina, quando usadas na profilaxia da influenza em idosos moradores em asilos ${ }^{(104)}$. Sua eliminação é primariamente através dos rins, devendo-se observar a função renal, já que existe a possibilidade de nefrotoxicidade ${ }^{(86)}$.

\section{ZANAMIVIR/OSELTAMIVIR}

A enzima neuraminidase é uma glicoproteína de superfície, essencial para a replicação do vírus da influenza tipo $\mathrm{A}$ e $\mathrm{B}^{(108)}$. A neuraminidase promove a liberação do vírus da influenza das células infectadas e facilita a disseminação do vírus no trato respiratório. Recentemente, foram desenvolvidos inibidores específicos da neuraminidase do Myxovirus influenzae tipo A e B, que têm utilização profilática e terapêutica ${ }^{(109)}$. Embora o vírus da influenza modifique sua estrutura antigênica anualmente, o sítio ativo da neuraminidase é altamente preservado em todas as cepas clinicamente relevantes, tornando a neuraminidase um alvo ideal para a intervenção antiviral. Os inibidores da neuraminidase representam um avanço importante no tratamento da influenza, porque têm um espectro antiviral maior que os vistos com os inibidores $\mathrm{M}_{2}$, assim como melhor tolerância e potencial menor para a emergência de resistência ${ }^{(110)}$. Entretanto, o uso indiscriminado dos inibidores da neuraminidase pode levar ao surgimento de resistência, sendo que desde já estão sendo analisados os mecanismos de resistência dos mutantes e desenvolvendo-se testes para determinar a suscetibilidade dos mesmos ${ }^{(111-114)}$.

O primeiro desse tipo de compostos a surgir foi o zanamivir, o qual não é ativo por via oral, sendo administrado por pó inalado ou por via intranasal (spray ou gotas). O zanamivir é aprovado para tratamento da doença aguda causada por influenza em pessoas com idade igual ou superior a 12 anos, que apresentam sintomas por não mais que dois dias, quando o vírus está circulando na co- munidade ${ }^{(115)}$. O zanamivir tem indicação precoce para tratamento curativo da influenza, assim que os primeiros sintomas surgem, particularmente em pacientes idosos vacinados (a vacinação é efetiva em somente 70 a $80 \%$ dos casos) ${ }^{(116)}$. Não é aprovado para profilaxia da influenza. Tem-se mostrado eficaz comparado com placebo, reduzindo a duração e intensidade dos sintomas da gripe com boa tolerância ${ }^{(105)}$, assim como reduz o consumo de antibióticos para complicações relacionadas à influen$\mathrm{za}^{(108,116)}$. O tempo médio para alívio dos sintomas maiores foi reduzido entre 1 e 2,5 dias após o tratamento com zanamivir, sendo esta redução de 2,5 a 3,2 dias nos pacientes de alto risco(108,117). São relatados benefícios do tratamento com essa droga, reduzindo o tempo de volta às atividades normais, o consumo do paracetamol (acetaminofeno) e o nível de interferência da influenza no sono, trabalho, descanso e atividades de recreação(108).

A suscetibilidade ao zanamivir é extremamente variável mesmo antes do tratamento, não se correlacionando com a velocidade da eliminação viral. Isolados com aparente limitada suscetibilidade ao zanamivir provaram ser suscetíveis in vivo na doninha. Análise seqüencial não revelou alterações na hemaglutinina e genes da neuraminidase na maioria dos isolados, sendo que as poucas alterações observadas foram todas variantes naturais. Alterações aminoácidas que tenham sido previamente identificadas in vitro não foram envolvidas com diminuição da suscetibilidade. Em trabalhos clínicos, houve redução da contagem viral após 24 horas de tratamento, sem reemergência do vírus até o final do tratamento, não surgindo mudança na suscetibilidade ao zanamivir antes e após o tratamento ${ }^{(118)}$.

O efeito do zanamivir inalado no tratamento da influenza foi avaliado no Canadá em 1997-1998. Após somente 12 horas de tratamento (uma dose), os títulos virais nas secreções faringeas haviam diminuído. Houve redução de $47 \%$ no tempo médio de alívio dos sintomas, não sendo detectadas amostras virais resistentes ao zanamivir. A dose utilizada do zanamivir inalado, sob forma de pó seco, foi de $10 \mathrm{mg}$ duas vezes por dia, por cinco dias, iniciado no primeiro ou segundo dia da doença ${ }^{(119)}$. O uso intranasal do zanamivir é feito duas a seis vezes por dia, por quatro a cinco dias, iniciando quatro horas antes até um a dois dias após a inoculação com vírus da influen$\mathrm{za}^{(120)}$. Há trabalho demonstrando que o tratamento de curta duração (cinco dias) com zanamivir intranasal é ineficaz ${ }^{(121)}$. Matsumoto et al. ${ }^{(122)}$, utilizando o zanamivir por via inalatória e inalatória mais spray intranasal em adultos, demonstraram que os pacientes que receberam 0 zanamivir recuperaram-se significantemente mais rápido, tendo sido o mesmo bem tolerado. Efeitos adversos do zanamivir terapeuticamente ou profilaticamente parecem similares aos dos pacientes recebendo placebo. Os efei- 
tos adversos mais freqüentemente relatados em estudos terapêuticos foram sinais e sintomas nasais, diarréia, náusea, cefaléia, bronquite e tosse $e^{(108)}$.

A indicação potencial do zanamivir como profilático foi demonstrado em asilo, quando a incidência da influenza A sofreu redução com o uso do zanamivir, $10 \mathrm{mg}$ por inalação oral, uma vez por dia durante quatro semanas ${ }^{(108)}$. Fenton et al. ${ }^{(123)}$ mostraram que a administração profilática do zanamivir, quando a droga é dada em dose única por via intranasal, pode reduzir significantemente os títulos do vírus no pulmão de ratos, também diminuindo tanto os títulos virais como os sintomas nas doninhas. Estes resultados indicam que o zanamivir pode ter validade clínica como agente profilático, protegendo grupos de alto risco da infecção por influenza.

Mais recentemente, surgiu o fosfato de oseltamivir, que é um forte inibidor seletivo da neuraminidase dos vírus da influenza A e B. Tanto o zanamivir quanto o oseltamivir foram aprovados nos Estados Unidos em 1999, não estando aprovados para profilaxia da influenza ${ }^{(115)}$. O oseltamivir leva à formação do metabólito ativo, que é detectável no plasma dentro de 30 minutos, alcançando as concentrações máximas após três a quatro horas. A meiavida do metabólito ativo é de seis a dez horas na maioria dos pacientes. Concentrações plasmáticas constantes são alcançadas dentro de três dias da administração duas vezes por dia e, na dosagem de $75 \mathrm{mg}$ duas vezes por dia, a concentração do metabólito ativo permanece acima da concentração inibitória mínima de todas as amostras de influenza testadas ${ }^{(124)}$. É distribuído em todos os tecidos, incluindo os maiores sítios de infecção (pulmão, mucosa nasal e ouvido médio) ${ }^{(125)}$. Em ratos, foi demonstrado que o uso do oseltamivir não afetou adversamente as respostas celulares e humorais ao vírus da influenza in vivo ${ }^{(126)}$.

Para tratamento da infecção por influenza, utiliza-se, por via oral, a dose de 75 ou $150 \mathrm{mg}$ duas vezes ao dia por cinco dias e, como profilático, a dose de $75 \mathrm{mg}$ uma ou duas vezes ao dia por seis semanas ${ }^{(127)}$. Foi demonstrada sua eficácia quando administrada no período de até 36 horas após o aparecimento dos sintomas, reduzindo a duração e gravidade destes e a incidência de complicações secundárias ${ }^{(125,126)}$. Treanor et al. ${ }^{(128)}$ mostraram que oseltamivir fornecido nas doses de 75 e $150 \mathrm{mg}$, duas vezes por dia, reduziu a duração e a gravidade da influenza A em indivíduos sadios, diminuindo também a incidência de complicações secundárias como bronquite e sinusite. Ainda não está demonstrada sua eficácia terapêutica em grupos de risco e na influenza $\mathrm{B}$, enquanto estudos sobre sua eficácia como profilática estão ainda em andamento. A administração profilática do oseltamivir por via oral foi eficaz em voluntários saudáveis não-imunizados durante período de influenza, sendo baixa a incidência de resistência viral ${ }^{(125)}$.
A farmacocinética naqueles com influenza é qualitativamente idêntica à dos indivíduos jovens sãos. Estudos in vivo e in vitro indicam que não há interação clinicamente significante entre drogas. Nem paracetamol nem cimetidina alteram a farmacocinética do oseltamivir. Coadministração de probenecid resulta em aumento de 2,5 a cinco vezes na exposição ao oseltamivir, mas esta competição não é provável que resulte em efeitos clínicos relevantes. Exposição do metabólito ativo em concentrações constantes é aproximadamente 25 vezes maior em idosos comparados com indivíduos jovens. Entretanto, a diferença de disponibilidade da medicação entre indivíduos jovens e idosos não foi suficiente para necessitar de ajustes da dose nos idosos. O oseltamivir absorvido é eliminado, principalmente (> 90\%) pela conversão para o metabólito ativo, que não é metabolizado, na urina. A droga ativa é eliminada completamente por excreção renal. Em pacientes com insuficiência renal, o clearance do metabólito diminuiu linearmente com o clearance da creatinina. É recomendado ajuste da dose em pacientes com clearance de creatinina menor do que $30 \mathrm{ml} / \mathrm{min}(1,8 \mathrm{~L} / \mathrm{h})$, sendo usada a redução para $75 \mathrm{mg}$ uma vez por dia(124).

O oseltamivir pode provocar efeitos colaterais relacionados ao trato gastrintestinal, principalmente náuseas e vômitos, que habitualmente são discretos e de natureza transitória ${ }^{(125)}$. Outros eventos adversos, encontrados raramente, foram insônia, enxaqueca e dor abdominal. A administração com o alimento pode aumentar a tolerabilidade em alguns pacientes. Até o presente, não há dados disponiveis que permitam avaliar o potencial do fosfato de oseltamivir em causar malformações fetais ou toxicidade fetal quando utilizado em mulheres grávidas. Em ratos, durante a lactação, o oseltamivir e seu metabólito ativo são excretados no leite ${ }^{(129)}$.

\section{AVALIAÇÃo}

Infecções por vírus são de alto risco em grupos de indivíduos como crianças pequenas, idosos e pacientes com doenças cardiopulmonares ou imunocomprometidos, causando graves manifestações, que freqüentemente resultam em fatalidades. Atualmente, na prática clínica, a vacinação é a única eficaz contra a influenza. Os novos compostos são agentes complementares, sendo usados em combinação com a vacinação, mas não são substitutos da mesma(115). Para evitar o uso inapropriado desses agentes, tratamento deve ser continuado somente nos pacientes com diagnóstico confirmado de influenza. Embora eficaz na diminuição dos sintomas, nenhum desses agentes previne a pneumonia ou hospitalização secundárias à influenza ${ }^{(130)}$.

Enquanto a vacinação em população selecionada permanece a intervenção de escolha na profilaxia, a eficá- 
cia, a boa tolerabilidade e a perda de resistência vistos com os inibidores da neuraminidase provavelmente farão dessas drogas uma opção de tratamento válido, particularmente em indivíduos não cobertos ou inadequadamente protegidos pela vacina e naqueles com alto risco de complicações relacionadas à influenza. Confirmação da eficácia profilática dessas drogas poderia indicar um papel potencial maior, especialmente naqueles nos quais a vacinação não foi possivel ou não foi inteiramente eficaz, em comunidades fechadas (como asilos) e em indivíduos de alto risco(108).

Antivirais podem ser úteis como adjuvantes à vacinação, especialmente para controle de epidemias em instituições ${ }^{(131)}$. Os antivirais em uso e em desenvolvimento quase certamente serão ativos contra variante pandêmica. O uso durante pandemias deve ser extenso, mas pode ser limitado pela quantidade de droga disponível, a logística da estocagem e distribuição, assim como com a possibilidade de efeitos colaterais ${ }^{(57)}$.

\section{REFERÊNCIAS}

1. Nair MP, Kronfol ZA, Schwartz SA. Effects of alcohol and nicotine on cytotoxic functions of human lymphocytes. Clin Immunol Immunopathol 1990;54:395-409.

2. Glezen WP, Greenberg SB, Atmar RL, Piedra PA, Couch RB. Impact of respiratory virus infections on persons with chronic underlying conditions. JAMA 2000;283:499-505.

3. Watanakunakorn C, Bailey TA. Adult bacteremic pneumococcal pneumonia in a community teaching hospital, 1992-1996. A detailed analysis of 108 cases. Arch Intern Med 1997;157:1965-1971.

4. Connolly AM, Salmon RL, Lervy B, et al. What are the complications of influenza and can they be prevented? Experience from the 1989 epidemic of $\mathrm{H}_{3} \mathrm{~N}_{2}$ influenza $\mathrm{A}$ in general practice. BMJ 1993;306: 1452-1454.

5. Murphy BR, Webster RG. In: Fields B, et al, eds. Field's virology. $3^{\text {th }}$ ed. Philadelphia: Lippincott-Raven, 1996;1397-1445.

6. www.fns.gov.br/not/not14.htm

7. Fine MJ, Smith DN, Daniel E, et al. Hospitalization decision in patients with community-acquired pneumonia. A prospective cohort study. Am J Med 1990;89:713-721.

8. Barker W, Mullooly J. Impact of epidemic type A influenza in a defined adult population. Am J Epidemiol 1980;115:798-813.

9. Simons RJ, Reynolds HY. Altered immune status in the elderly. Semin Respir Infect 1990;5:251-259.

10. Torres A, El-Ebiary M, Riqueline R, Ruiz M, Celis R. Community-acquired pneumonia in the elderly. Semin Respir Infect 1999;14:173183.

11. Koivula I, Stern M, Makela PH. Risk factors for pneumonia in the elderly. Am J Med 1994;96:313-320.

12. Riquelme R, Torres A, El-Ebiary M, Puig de la Bellacasa, Estrich, Mensa J, Fernandez-Sola J, Hernandez C, Rodriguez-Roisin R. Community-acquired pneumonia in the elderly. Multivariate analysis of risk and prognostic factors. Am J Respir Crit Care Med 1996;154:1450-1455.

13. Ruiz M, Ewig S, Marcos MA, Martinez JA, Arancibia F, Mensa J, Torres A. Etiology of community-acquired pneumonia: impact of age, comorbidity, and severity. Am J Respir Crit Care Med 1999;160:397-405.
14. Sherman CB. The health consequences of cigarette smoking: pulmonary diseases. Med Clin North Am 1992;76:355-375.

15. Ginesu F, Pirina P. Etiology and risk factors of adult pneumonia. J Chemother 1995; 7:277-285.

16. Soler N, Torres A, Ewig S, et al. Bronchial microbial patterns in severe exacerbations of chronic obstructive pulmonary disease (COPD) requiring mechanical ventilation. Am J Respir Crit Care Med 1998;157: 1498-1505.

17. Carstensen JM, Pershagen G, Eklund G. Mortality in relation to cigarette and pipe smoking: 16 years observation of 25,000 Swedish men. J Epidemiol Community Health 1987;41:166-172.

18. Almirall J, González CA, Balanzó X, Bolíbar I. Proportion of community-acquired pneumonia cases attributable to tobacco smoking. Chest 1999;116:375-379.

19. LaCroix AZ, Lipson S, Miles T, White L. Prospective study of pneumonia hospitalizations and mortality of U.S. older people: the role of chronic conditions, health behaviors and nutritional status. Public Health Rep 1989;104:350-369.

20. Esposito AL. Pneumonia in the elderly. In: Pennington JE, ed. Respiratory infections. Diagnosis and management. $3^{\text {th }}$ ed. New York: Raven Press, 1994;257-274.

21. Mobbs KJ, Van Saene HKF, Sunderland D, Davies PDO. Oropharyngeal gram-negative bacillary carriage. A survey of 120 healthy individuals. Chest 1999;115:1570-1575.

22. Beachey EH. Bacterial adherence: adhesin-receptor interactions mediating the attachment of bacteria to mucosal surfaces. J Infect Dis 1981; 143:325-345.

23. Valenti BM, Trudell RG, Bentley DW. Factors predisposing to oropharyngeal colonization with gram-negative bacilli in the aged. N Engl $\mathrm{J}$ Med 1978;298:1148-1151.

24. Wolf B, Gama A, Rey L, et al. Striking differences in the nasopharyngeal flora of healthy Angolan, Brazilian and Dutch children less than 5 years old. Ann Trop Paediatr 1999;19:287-292.

25. Tracy JF, Logemann JA, Kahrilas PJ, Jacob P, Kobara M, Krugler C. Preliminary observations on the effects of age on oropharyngeal deglutition. Dysphagia 1989;4:90-94.

26. Huxley E, Viroslav J, Gray W, et al. Pharyngeal aspiration in normal adults and patients with depressed consciousness. Am J Med 1978; 64:564-568.

27. Sasaki H, Pinto A, Yanai M, Nakagawa T, Sekizawa K. Swallowing reflex in the night in the elderly subjects. Am J Respir Crit Care Med 1995;151(pt 2):A719.

28. Nilsson H, Ekberg O, Olsson R, Hindfelt B. Dysphagia in stroke: a prospective study of quantitative aspects of swallowing in dysphagic patients. Dysphagia 1998;13:32-38.

29. Kikuchi R, Watabe N, Konno T, Mishima N, Sekizawa K, Sasaki H. High incidence of silent aspiration in elderly patients with communityacquired pneumonia. Am J Resp Crit Care Med 1994;150:252-254.

30. Saitz R, Ghali WA, Moskowitz MA. The impact of alcohol-related diagnosis on pneumonia outcomes. Arch Intern Med 1997;157:1446-1452.

31. Ruiz M, Ewig S, Torres A, et al. Severe community-acquired pneumonia: risk factors and follow-up epidemiology. Am J Respir Crit Care Med 1999;160:923-929.

32. Chandra R. The relation between immunology, nutrition and disease in elderly people. Age Ageing 1990;19:S25-S31.

33. Fletcher J, Little J, Walker P. Anergy and the severely ill surgical patient. Aust N Z J Surg 1986;56:117-120.

34. Victora CG, Kirkwood BR, Ashworth A, et al. Potential interventions for the prevention of childhood pneumonia in developing countries: improving nutrition. Am J Clin Nutr 1999;70:309-320. 
35. Gilson KF. Respiratory disease in minorities: issues of access, race, and ethnicity. Am J Respir Crit Care Med 1994;149:570-571.

36. Baker H, Frank O, Thind IS, Jaslow SP, Louria DB. Vitamin profiles in elderly persons living at home or in nursing homes, versus profile in healthy young subjects. J Am Geriatr Soc 1979;27:444-450.

37. Duchateau J, Delepesse G, Vrijens R, Collet H. Beneficial effects of oral zinc supplementation on the immune response of old people. Am J Med 1981;70:1001-1004.

38. Stuck AE, Minder CE, Frey F. Risk of infectious complications in patients taking glucocorticosteroids. Rev Infect Dis 1989;11:954-963.

39. Bohm GM, Saldiva PHN, Pasqualucci CAG, et al. Biological effects of air pollution in São Paulo and Cubatão. Environ Res 1989;49:208216.

40. Saldiva PHN, King M, Delmonte VLC, et al. Respiratory alterations due to urban air pollution: an experimental study in rats. Environ Res 1990;57:19-33.

41. Capelozzi VL. Efeitos da poluição, tabagismo e poeiras minerais sobre o aparelho respiratório. In: Algranti E, Greco L, eds. Doenças ocupacionais pulmonares. São Paulo: Serviço Social da Indústria, Sociedade Brasileira de Pneumologia e Tisiologia, 1997.

42. Schartz J. Air pollution and hospital admissions for the elderly in Detroit, Michigan. Am J Respir Crit Care Med 1994;150:648-655.

43. Sologuren MJJ, Rivoiro A, Tomiyama E, Miranda GP. O padrão sazonal das pneumonias em Uberlândia, MG. J Pneumol 1992;18(Supl 2):32.

44. Influenza and pneumococcal vaccination rates among persons with diabetes mellitus-United States, 1997. MMWR Morb Mortal Wkly Rep 1999;48:961-967.

45. Noble G. In: Beare A, Boca RF, eds. Basic and applied influenza research. CRC Press, 1982;11-50.

46. Eickhoff TC, Sherman IL, Serfling RE. Observations on excess mortality associated with epidemic influenza. JAMA 1961;176:776-782.

47. Nguyen-Van-Tam JS, Neal KR. Clinical effectiveness, policies, and practices for influenza and pneumococcal vaccines. Semin Respir Infect 1999;14:184-195.

48. Kilbourne ED. Inactivated influenza vaccines. In: Plotkin AS, Mortimer Jr. EA, eds. Vaccines. Philadelphia: W.B. Saunders, 1988;420.

49. Nguyen-Van-Tam JS, Nicholson KG. Influenza deaths in Leicestershire during the 1989-90 epidemic. Implications for prevention. Epidemiol Infect 1992;108:537-545.

50. Nichol K, Lind A, Margolis K, et al. The effectiveness of vaccination against influenza in health working adults. N Engl J Med 1995;333: 889-893.

51. Adult influenza vaccination guideline. SAMA-AS Pulmonology Society Working Group. S Afr Med J 1999;89(Suppl 11):1216-1222.

52. Nichol KL, Goodman M. The health and economic benefits of influenza vaccination for healthy and at-risk persons aged 65 to 74 years. Pharmacoeconomics 1999;16(Suppl 1):63-71.

53. Remarque EJ. Influenza vaccination in elderly people. Exp Gerontol 1999;34:445-452.

54. Nichol KL, Baken L, Nelson A. Relation between influenza vaccination and outpatient visits, hospitalization and mortality in elderly persons with chronic lung disease. Ann Intern Med 1999;130:397-403.

55. Govaert TME, Thijs CTMCN, Masurel N, et al. The efficacy of influenza vaccination in elderly individuals: a randomized double-blind placebo-controlled trial. JAMA 1994;272:1661-1665.

56. Toniolo Neto J, Gorzoni ML. Imunização. In: Gorzoni ML, Toniolo Neto J, eds. Terapêutica clínica no idoso. São Paulo: Sarvier Editora de Livros Médicos Ltda., 1995;188-194.
57. Monto AS. Prospects for pandemic influenza control with currently available vaccines and antivirals. J Infect Dis 1997;176(Suppl 1):S32S37.

58. Ahmed AH, Nicholson KG, Nguyen-van Tam JS, Pearson JC. Effectiveness of influenza vaccine in reducing hospital admissions during the 1989-90 epidemic. Epidemiol Infect 1997;118:27-33.

59. Neuzil KM, Reed GW, Mitchel EF Jr, Griffin MR. Influenza-associated morbidity and mortality in young and middle-aged women. JAMA 1999; 281:901-907.

60. Koziel H, Koziel MJ. Pulmonary complications of diabetes mellitus: pneumonia. Infect Dis Clin North Am 1995;9:65-96.

61. Colquhoun AJ, Nicholson KG, Botha JL, Raymond NT. Effectiveness of influenza vaccine in reducing hospital admissions in people with diabetes. Epidemiol Infect 1997;119:335-341.

62. Margolis KL, Nichol KL, Poland GA. Frequency of adverses reactions to influenza vaccine in the elderly. JAMA 1990;264:1159.

63. Safranek TJ, Lawrence DN, Kurland LT. Reassessment of the association between Guillain-Barret syndrome and receipt of the swine influenza vaccine in 1976-1977. Am J Epidemiol 1991;133:940.

64. Floret D. Virus-bacteria co-infections. Arch Pediatr 1997;4:1149-1154.

65. Gorse GJ, Otto EE, Daughaday CC. Influenza virus vaccination of patients with chronic lung disease. Chest 1997;115:1221-1233.

66. Austrian R. Random gleanings from a life with the pneumococcus. J Infect Dis $1975 ; 131: 474-484$.

67. Shapiro ED, Berg AT, Austrian R, et al. The protective efficacy of polyvalent pneumococcal polysaccharide vaccine. N Engl J Med 1991; 325:1453-1460.

68. Hager HL, Woolley TW, Berk SL. Review of recent pneumococcal infectious with attention to vaccine and non vaccines sorotypes. Rev Infect Dis 1991;12:267.

69. Bentley DW, Mylotte JM. Epidemiology of respiratory infections in the elderly. In: Niederman MS, ed. Respiratory infections in the elderly. New York: Raven Press, 1991;1-23.

70. Raz R, Elhanan G, Shimoni Z. Pneumococcal bacteremia in hospitalized Israeli adults: epidemiology and resistance to penicillin. Israeli Adult Pneumococcal Bacteremia Group. Clin Infect Dis 1997;24:1164-1168.

71. Riley IR, Tarr P, Andrews M. Immunization with a polyvalent pneumococcal vaccine: reduction in adult respiratory mortality in a New Guinean highlands community. Lancet 1977;i:1338-1341.

72. Fedson DS. Adult immunization. Summary of the National Vaccine Advisory Committee Report (Special Communication). JAMA 1994; 14:1153.

73. Ortqvist A, Hedlund J, Kalin M. The elderly should be vaccinated against pneumococci. Lakartidningen 1999;96:1305-1308.

74. Adult pneumococcal vaccination guideline. SAMA-SA Pulmonology Society Working Group. S Afr Med J 1999;89(Suppl 11):1222-1230.

75. Silva LR. Imunização ativa e passiva. In: Silva P. Farmacologia. 4a ed, Rio de Janeiro: Ed. Guanabara Koogan, 1994;513-531.

76. Fine M, Smith M, Carson C, et al. Efficacy of pneumococcal vaccination in adults: a meta-analysis of randomized controlled trials. Arch Intern Med 1994;154:2666-2677.

77. Fine MJ, Smith MA, Carson CA, et al. Efficacy of pneumococcal vaccination in adults. Arch Intern Med 1994;154:2666-2677.

78. Fedson DS. The clinical effectiveness of pneumococcal vaccination: a brief review. Vaccine 1999;17(Suppl 1):S85-S90.

79. Roghmann KJ, Tabliski PA, Bentley DW, Schiffman G. Immune response of elderly adults to pneumococcus: variation by age, sex, and functional impairment. J Gerontol 1987;42:265-270. 
80. Sims RV, Steinmann WC, McConville JH, King LR, Zwick WC, Schwartz JS. The clinical effectiveness of pneumococcal vaccine in the elderly. Ann Intern Med 1988;108:653-657.

81. Hanna JN, Gratten M, Tiley SM, Brookes DL, Bapty G. Pneumococcal vaccination: an important strategy to prevent pneumonia in Aboriginal and Torres Strait Island adults. Aust N Z J Public Health 1997; 21:281-285

82. Kazancioglu R, Sever MS, Yuksel-Onel D, et al. Immunization of renal transplant recipients with pneumococcal polysaccharide vaccine. Clin Transplant 2000;14:61-65.

83. Bouter KP, Diepersloot RJ, Van Romunde LK, et al. Effect of epidemic influenza on ketoacidosis, pneumonia and death in diabetes mellitus: a hospital register survey of 1976-1979 in the Netherlands. Diabetes Res Clin Pract 1991;12:61-68.

84. Singer NG, McCune WJ. Prevention of infectious complications in rheumatic disease patients: immunization, Pneumocystis carinii prophylaxis, and screening for latent infections. Curr Opin Rheumatol 1999; 11:173-178.

85. Santamauro JT, White DA. Respiratory infections in HIV-negative immunocompromised patients. Curr Opin Pulm Med 1996;2:253258.

86. Arunabh, Niederman MS. Strategies for prevention of communityacquired pneumonia. Sem Respir Infect 1998;13:68-78.

87. Guerrero M, Kruger S, Saitoh A, et al. Pneumonia in HIV-infected patients: a case-control survey of factors involved in risk and prevention. AIDS 1999;13:1971-1975.

88. Gebo KA, Moore RD, Keruly JC, Chaisson RE. Risk factors for pneumococcal disease in human immunodeficiency virus-infected patients. $\mathrm{J}$ Infect Dis 1996;173:857-862.

89. Borgono JM, McLean AA, Vella PP. Vaccination and revaccination with polyvalent pneumococcal polysaccharide vaccines in adults and infants. Proc Soc Exp Biol Med 1978;157:148-154.

90. US Dept of Health and Human Services. Prevention of pneumococcal disease. Recommendations of the Advisory Committee on Immunization Practices (ACIP). MMWR Morb Mortal Wkly Rep 1997;46(RR8):1-24.

91. Ortqvist A, Hedlund J, Burman LA, et al. Randomized trial of 23valent pneumococcal capsular polysaccharide vaccine in prevention of pneumonia in middle-aged and elderly people. Swedish Pneumococcal Vaccination Study Group. Lancet 1998;351:399-403.

92. Koivula I, Sten M, Leinonen M, Makela PH. Clinical efficacy of pneumococcal vaccine in the elderly: a randomized, single-blind population-based trial. Am J Med 1997;103:281-290.

93. Hutchison BG, Oxman AD, Shannon HS, Lloyd S, Altmayer CA, Thomas K. Clinical effectiveness of pneumococcal vaccine. Meta-analysis. Can Fam Physician 1999;45:2381-2393.

94. Nichol KL, Baken L, Wuorenma J, Nelson A. The health and economic benefits associated with pneumococcal vaccination of elderly persons with chronic lung disease. Arch Intern Med 1999;159:24372442.

95. Butler JC, Breiman RF, Campbell JF, et al. Pneumococcal polysaccharide vaccine efficacy. An evaluation of current recommendations. JAMA 1993;270:1826-1831.

96. McIntyre P. Epidemiology and prevention of pneumococcal disease. Commun Dis Intell 1997;21:41-46.

97. Hulsse C, Littmann M, Fiedler K, Kaltofen U, Hundt C. Epidemiology and serologic studies of pneumococcal infection with reference to the new STIKO recommendations. Gesundheitswesen 1999;61:393-397.

98. Hueston WJ, Mainous AG $3^{\text {rd }}$, Brauer N. Predicting cos-benefits before programs are started: looking at conjugate vaccine for invasive pneumococcal infections. J Community Health 2000;25:23-33.
99. Silk H, Zora J, Goldstein J, Tinkelman D, Schiffman G. Response to pneumococcal immunization in children with and without recurrent infections. J Asthma 1998;35:101-115.

100. Nichol KL. The additive benefits of influenza and pneumococcal vaccinations during influenza seasons among elderly persons with chronic disease. Vaccine 1999;17(Suppl 1):S91-S93.

101. Honkanen PO, Keistinen T, Miettinen L, et al. Incremental effectiveness of pneumococcal vaccine on simultaneously administered influenza vaccine in preventing pneumonia and pneumococcal pneumonia among persons aged 65 years or older. Vaccine 1999;17:24932500.

102. Jacobson TA, Thomas DM, Morton FJ, Offutt G, Shevlin J, Ray S. Use of a low-literacy patient education tool to enhance pneumococcal vaccination rates. A randomized controlled trial. JAMA 1999; 282:646-650.

103. Vold Pepper P, Owens DK. Cost-effectiveness of the pneumococcal vaccine in the United States Navy and Marine Corps. Clin Infect Dis 2000;30:157-164.

104. Keyser LA, Karl M, Nafziger AN, Bertino Jr. JS. Comparison of central nervous system adverse effects of amantadine and rimantadine used as sequential prophylaxis of influenza $\mathrm{A}$ in elderly nursing home patients. Arch Intern Med 2000;160:1485-1488.

105. Demicheli V, Jefferson T, Rivetti D, Deeks J. Prevention and early treatment of influenza in healthy adults. Vaccine 2000;18:957-1030.

106. Prevention and control of influenza: recommendations of the Advisory Committee on Immunization Practices (ACIP). MMWR Morb Mortal Wkly Rep 1999;30:1-28.

107. Bricaire F. Influenza: new therapeutic perspectives. Presse Med 1998; 27(Suppl 5):24-26.

108. Dunn CJ, Goa KL. Zanamivir: a review of its use in influenza. Drugs 1999;58:761-784.

109. Stamboulian D, Bonvehi PE, Nacinovich FM, Cox N. Influenza. Infect Dis Clin North Am 2000;14:141-166.

110. Buxton RC, Edwards B, Juo RR, Voyta JC, Tisdale M, Bethell RC. Development of a sensitive chemiluminescent neuraminidase assay for the determination of influenza virus susceptibility to zanamivir. Anal Biochem 2000;280:291-300.

111. Tisdale M. Monitoring of viral susceptibility: new challenges with the development of influenza NA inhibitors. Rev Med Virol 2000;10:4555.

112. Shigeta S. Recent progress in anti-influenza chemotherapy. Drugs $R$ D 1999;2:153-164.

113. Barnett JM, Cadman A, Burrell FM, et al. In vitro selection and characterization of influenza B/Beijing/1/87 isolates with altered susceptibility to zanamivir. Virology 1999;265:286-295.

114. Gubareva LV, Kaiser L, Hayden FG. Influenza virus neuraminidase inhibitors. Lancet 2000;355:827-835.

115. Neuraminidase inhibitors for treatment of influenza A and B infections. MMWR Morb Mortal Wkly Rep 1999;48:1-9.

116. Le Moing V. De nouveaux antiviraux pour les viroses respiratoires. Presse Med 199;28(Suppl 3):22-24.

117. Silagy CA, Campion K. Effectiveness and role of zanamivir in the treatment of influenza infection. Ann Med 1999;31:313-317.

118. Barnett JM, Cadman A, Gor D, et al. Zanamivir susceptibility monitoring and characterization of influenza virus clinical isolates obtained during phase II clinical efficacy studies. Antimicrob Agents Chemother 2000;44:78-87.

119. Boivin G, Goyette N, Hardy I, Aoki F, Wagner A, Trottier S. Rapid antiviral effect of inhaled zanamivir in the treatment of naturally occurring influenza in otherwise healthy adults. J Infect Dis 2000;181: $1471-1474$. 
120. Peng AW, Hussey EK, Moore KH. A population pharmacokinetic analysis of zanamivir in subjects with experimental and naturally occurring influenza: effects of formulation and route of administration. J Clin Pharmacol 2000;40:242-249.

121. Kaiser L, Henry D, Flack NP, Keene O, Hayden FG. Short-term treatment with zanamivir to prevent influenza: results of a placebo-controlled study. Clin Infect Dis 2000;30:587-589.

122. Matsumoto K, Ogawa N, Nerome K, et al. Safety and efficacy of the neuraminidase inhibitor zanamivir in treating influenza virus infection in adults: results from Japan. GG 167 Group. Antivir Ther 1999;4: 61-68.

123. Fenton RJ, Morley PJ, Owens IJ, Gower D, Parry S, Crossman L, Wong T. Chemoprophylaxis of influenza A virus infections, with single doses of zanamivir, demonstrates that zanamivir is cleared slowly from the respiratory tract. Antimicrob Agents Chemother 1999;43: 2642-2647.

124. He G, Massarella J, Ward P. Clinical pharmacokinetics of the prodrug oseltamivir and its active metabolite Ro 64-0802. Clin Pharmacokinet 1999;37:471-484.

125. Bardsley-Elliot A, Noble S. Oseltamivir. Drugs 1999;58:851-860.
126. Hayden FG, Treanor JJ, Fritz RS, et al. Use of the oral neuraminidase inhibitor oseltamivir in experimental human influenza: randomized, controlled trials for prevention and treatment. JAMA 1999;282: 1240-1246.

127. Long JK, Mossad SB, Goldman MP. Antiviral agents for treating influenza. Cleve Clin J Med 2000;67:92-95.

128. Treanor JJ, Hayden FG, Vrooman PS, Barbarash R, Bettis R, Riff D, et al. Efficacy and safety of the oral neuraminidase inhibitor oseltamivir in treating acute influenza: a randomized controlled trial. US Oral Neuraminidase Study Group. JAMA 2000;283:1016-1024.

129. Burger RA, Billingsley JL, Huffman JH, Bailey KW, Kim CU, Sidwell RW. Immunological effects of the orally administered neuraminidase inhibitor oseltamivir in influenza virus-infected and uninfected mice. Immunopharmacology 2000;47:45-52.

130. Long JK, Mossad SB, Goldman MP. Antiviral agents for treating influenza. Cleve Clin J Med 2000;67:92-95.

131. Arden NH. Control of influenza in the long-term-care facility: a review of established approaches and newer options. Infect Control Hosp Epidemiol 2000;21:59-64. 